\title{
Predictive Factors of Inadvertent Durotomy in Lumbosacral Prolapsed Intervertebral Disc Surgeries: A Retrospective Review at a Tertiary Care Centre in India
}

\author{
Ajay Sebastian Carvalho $M C h^{1}$, Kishan Kumar Yadav $M C^{2}$, Arjun MN DNB ${ }^{3}$, Ashok Kumar $M C h^{4}$, Roopa \\ Shivashankar $M D^{5}$, Vijay Kumar Gupta $M C^{6} h^{6}$ \\ ${ }^{1}$ Department of Neurosurgery, Command Hospital (Southern Command), Pune, ${ }^{2}$ Department of Neurosurgery, Command \\ Hospital (Eastern Command), Kolkata, ${ }^{3,4}$ Department of Neurosurgery, Command Hospital (Central Command), Lucknow \\ ${ }^{5}$ Centre for Chronic Disease Control (CDCC), Public Health Foundation of India, Gurgaon, Haryana, ${ }^{6}$ Department of \\ Neurosurgery, National Institute of Medical Sciences and Research, Jaipur, Rajasthan, India
}

Date of submission: $19^{\text {th }}$ August 2020

Date of acceptance: $18^{\text {th }}$ November 2020

Date of publication: $1^{\text {st }}$ December 2020

\section{Abstract}

Introduction: Inadvertent dural tear is an undesirable intraoperative complication of spine surgery, with a reported incidence range of $1.7 \%$ to $17 \%$. The purpose of this study is to determine the predictive factors of inadvertent durotomies (ID) in lumbosacral prolapsed disc surgeries and suggest a scoring system for pre-operative assessment of these predictors.

Methods and Materials: This is a retrospective observational study done in 230 patients operated for prolapsed lumbar intervertebral discs, between January 2010 to November 2012. The inadvertent dural tears were grouped as unrecognised, simple and complicated. Data were collected regarding diagnosis, comorbidities, surgical procedure, operating surgeon, prior spine surgeries, type of ID and complications.

Results: Of the 230 patients, ID was seen in $6.5 \%$ (15 patients). Higher incidences were noted in elderly (33.3\%) and obese (7.6\%). Bone nibbler and Kerrison's rongeur were the most common tools associated. Redo surgeries have a significant higher incidence (12.9\%) as compared to the first surgery $(5.53 \%)$.

Conclusions: The risk of ID in prolapsed lumbar intervertebral disc surgeries is high in presence of bony and ligamentous canal stenosis, instrument handling, and in smaller size of incisions. Additionally, elderly age of patients, obesity and surgeon fatigue appears to be a major determinant. Conscious effort to prevent this complication during surgery by predicting risks pre-operatively using a scoring system can aid in preventing ID.

Key words: Cerebrospinal fluid leak, Inadvertent durotomy, Lumbar spine, Pseudomeningocele

Access this article online

Website: https://www.nepjol.info/index.php/NJN

DOI: https://doi.org/10.3126/njn.v17i3.33118

HOW TO CITE

Carvalho AS, Yadav KK, MN A, Kumar A, Shivashankar R, Gupta VK. Predictive Factors of Inadvertent Durotomy in Lumbosacral Prolapsed Intervertebral Disc Surgeries: A Retrospective Review at a Tertiary Care Centre in India. NJNS. 2020;17(3):12-16

${ }^{1}$ ORCID id: 0000-0001-9558-7008

${ }^{2}$ ORCID id: 0000-0001-7817-1780

${ }^{3}$ ORCID id: 0000-0002-9231-3180

${ }^{4}$ ORCID id: 0000-0003-0752-1186

${ }^{5}$ ORCID id: 0000-0002-4361-9423

${ }^{6}$ ORCID id: 0000-0002-3959-3363

Copyright (C) 2020 Nepalese Society of Neurosurgeons (NESON)

ISSN: 1813-1948 (Print), 1813-1956 (Online)

This work is licensed under a Creative Commons Attribution-Non Commercial 4.0 International License.

\section{Introduction}

\begin{abstract}
Tnadvertent dural tear is a commonly encountered spine 1 surgeries in neurosurgical practice. The frequency mentioned in literature for lumbosacral surgeries varies from $1-17 \%^{1,2}, 3$, Potential causes include anatomic variations, dural adhesions, instrument slippage, obscured dural fold caught in rongeurs, thinned out dura in longstanding stenosis and possibly delayed leak by dural perforation due to a surgically created bony spicule. ${ }^{4}$ Failure of identifying the dorsal spino-dural ligamentous
\end{abstract}

\footnotetext{
Address for correspondence:

Ajay Sebastian Carvalho

Senior Adviser in Surgery \& Neurosurgeon,

Department of Neurosurgery,

Command Hospital (Southern Command), Pune, India

E-mail: ajayneuro0404@gmail.com

Phone: +91-7754935318
} 
structure other than the usual Hoffman's (ventrolateral) and Trolard's ligament (ventromedian) may lead to inadvertent durotomies (ID). ${ }^{5}$ ID may be noted during surgery or go unnoticed and leak/form a pseudomeningocele later.

In the published literature, many risk factors for ID are found. They include older age, male gender, type of procedure, ossification of posterior longitudinal ligament, osteoporosis, arthritis, diabetes and obesity. ${ }^{6,7}$ Other factors associated with higher incidence include the experience of the surgeon, revision surgeries and previous irradiations. ${ }^{8,9}$

In this study, we aim to identify the predictors of the inadvertent durotomy during lumbosacral spine surgery by the secondary analysis of the two years data in a tertiary care centre in India.

\section{Methods and Materials}

This was a retrospective observational study. We analyzed the data of 230 operated cases for prolapsed lumbosacral Intervertebral discs at the Neurosurgical OT of Command Hospital Southern Command (CHSC) and Armed Forces Medical College (AFMC) Pune, between Jan 2010 - Nov 2012. The study protocol was reviewed and approved by the reference ethics committee (Institutional ethical committee, Command Hospital Southern Command, Pune). Informed written consent as per protocol was obtained. We extracted the information on demographics, primary diagnosis, comorbidities, details of surgical procedures, operating surgeon, prior spine surgeries, incidental durotomy, complications and duration of post-operative stay from the clinical notes.

All data were entered in a spreadsheet and analyzed using Stata. Categorical variables were described by percentages and frequencies, whereas continuous variables were described by means and standard deviations. We cross-tabulated the cases of the ID and the non-ID with all the demographic, physiological, clinical and surgical variables. Student t-test was used to compare the means of the continuous variables and the Pearson's chi-squared test was used to assess the differences in the proportions between the two groups

All patients were operated for prolapsed lumbar intervertebral disc, elective or emergency, fresh or redo cases that have had either intra operative ID or postoperative CSF leak/operative site pseudomeningocele were included in our study. Patients who had incomplete data and PIVDs other than Lumbosacral region and those cases requiring instrumentation were excluded.

We stratified inadvertent durotomies as simple, complicated and unrecognised. Linear tears without prolapse of the nerve roots were termed as simple and irregular tears with prolapse of the nerve roots were termed as complicated. IDs not recognised per-operative but presented as CSF leaks from wound or pseudomeningocele post-operative were termed as unrecognized.

Once ID occurred the images were reviewed and all the findings of MRI were charted. Also noted was the experience of the surgeons, time of surgery performed on the operating day, (first/second/last surgery of the day). None of the surgeries were performed by residents as per the institute policy.

\section{Results}

A total of 230 case data were analysed. ID occurred in $15(6.5 \%)$ of the cases. Of the 15 ID patients, nine were males. Type of surgery was Microscopic Interlaminar discectomy in nine and laminectomy with discectomy in six. Among these 15 cases, one had lumbar canal stenosis only and the two patients had severe/extruded PIVDs.

Table 1 presents the stratification of demographic, physiological, clinical and surgery variables by the cases that resulted in ID vs no ID. Mean (SD) age of the patients were $43.61 \pm 13.34$ years. Incidence of inadvertent durotomy was higher in older patients $(33.3 \%$ in patients older than 50 years and $6.67 \%$ in patients younger than 30 years). Seven (7.6\%) of overweight patients had dural tear while $8(6.29 \%)$ of non-obese patients had dural tear. The incidence of ID was higher in revision procedures (12.9\%) than in first spinal surgeries (5.53\%) (Table1). All, except one, were caused by instruments. The most common instrument causing the tear was the Kerrison's rongeur followed by the bone nibbler. The commonest cause recognized was pinching of the dura by the instrument during removal of the ligamentum flavum/canal widening in a bony canal stenosis. All tears were recognized intraoperatively except one patient who had an unrecognized tear, which subsequently presented as post-operative CSF leak from the wound; hence the cause of the tear could not be ascertained. Morphologically, 6 were simple tears, 8 were complicated and 1 was unrecognized based on the defining criteria given above. 


\section{Carvalho et al}

\begin{tabular}{|c|c|c|c|c|c|c|}
\hline & & \multicolumn{2}{|c|}{ Non ID $(\mathrm{N}=215)$} & \multicolumn{2}{|c|}{ ID $(\mathrm{N}=15)$} & \multirow{2}{*}{$\begin{array}{c}\text { p- value } \\
\text { (Chi square test) }\end{array}$} \\
\hline & & $\mathbf{N}$ & $\%$ & $\mathrm{n}$ & $\%$ & \\
\hline \multirow{4}{*}{ Age (years) } & $18-29$ & 36 & 16.74 & 1 & 6.67 & 0.555 \\
\hline & $30-49$ & 107 & 49.77 & 9 & 60 & \\
\hline & $50+$ & 72 & 33.49 & 5 & 33.33 & \\
\hline & Mean (SD) & \multicolumn{2}{|c|}{$43.6(13.3)$} & \multicolumn{2}{|c|}{$45.6(8.6)$} & 0.5701 \\
\hline \multirow{2}{*}{ Sex } & Male & 129 & 60 & 9 & 60 & 1 \\
\hline & Female & 86 & 40 & 6 & 40 & \\
\hline \multirow{4}{*}{ BMI (kg/m2) } & $<25$ & 119 & 55.35 & 8 & 53.33 & \\
\hline & $25-30$ & 85 & 39.53 & 7 & 46.67 & 0.62 \\
\hline & $\geq 30$ & 11 & 5.12 & 0 & 0 & \\
\hline & Mean (SD) & \multicolumn{2}{|c|}{$24.9(2.6)$} & \multicolumn{2}{|c|}{$25.4(2.2)$} & 0.461 \\
\hline \multirow{2}{*}{ Hypertension } & yes & 46 & 21.4 & 5 & 33.33 & 0.282 \\
\hline & no & 169 & 78.6 & 10 & 66.67 & \\
\hline \multirow{2}{*}{ Diabetes Mellitus } & Yes & 18 & 8.37 & 1 & 6.67 & 0.817 \\
\hline & No & 197 & 91.63 & 14 & 93.33 & \\
\hline \multirow{2}{*}{$\begin{array}{l}\text { Coronary Artery } \\
\text { Disease }\end{array}$} & yes & 7 & 3.26 & 0 & 0 & 0.478 \\
\hline & No & 208 & 96.74 & 15 & 100 & \\
\hline \multirow{2}{*}{$\begin{array}{l}\text { Lumbar Canal } \\
\text { Stenosis (LCS) }\end{array}$} & Yes & 115 & 53.49 & 14 & 93.33 & 0.003 \\
\hline & No & 100 & 46.51 & 1 & 6.67 & \\
\hline \multirow{2}{*}{ Procedure } & ILD & 65 & 30.23 & 9 & 60 & \\
\hline & LAM & 150 & 69.77 & 6 & 40 & 0.017 \\
\hline \multirow{2}{*}{ Incision } & Large & 150 & 69.77 & 6 & 40 & \\
\hline & Small & 65 & 30.23 & 9 & 60 & 0.017 \\
\hline \multirow{2}{*}{ Redo surgery } & Yes & 27 & 87.1 & 4 & 12.9 & \\
\hline & No & 188 & 94.47 & 11 & 5.53 & 0.122 \\
\hline
\end{tabular}

Table 1: Comparison of demographic, clinical and surgical characteristics of study population with ID $(n=15)$ and non-ID $(n=215)$

\begin{tabular}{c|l|c}
\hline S. No & Factors & Score \\
\hline 1 & LCS & 1 \\
\hline 2 & Case of the Day $\left(2^{\text {nd }} / 3^{\text {rd }} /\right.$ Last $)$ & 1 \\
3 & Age $>50$ years & 1 \\
4 & Smaller Incision/exposure & 1 \\
5 & Obesity(BMI $>25)$ & 1 \\
6 & Re-Do Surgery & 3 \\
\hline
\end{tabular}

Table 2: Risk assessment scoring chart. Each factor is given a score of 1(one). The patient is considered to have low risk if the total points are less than 2, moderate risk 3-4 and high risk if the total is 5-6. Redo surgery is in itself a significant factor; hence we propose to give a score of 3 to it thus its presence increases the risk factor to at least moderate.

\section{Discussion}

Various methods have been described in literature to prevent inadvertent durotomies but none to predict their likelihood in a given case. The overall incidence of incidental durotomy varies from $1.7 \%$ to $16 \%$ in the literature. In our study inadvertent durotomy (ID) occurred in $(6.5 \%)$ of patients. Higher incidences of ID were noted in patients in the third and the fourth decade, $(60 \%)$, there were 27 redo surgeries and the incidence of ID among 
them was $04(12.9 \%)$ and obese patients (7.6\%). Bony nibbler and Kerrison's Ronguer are the most common tools associated with ID and must be used with caution during surgeries.

Sin et al. reported $15.8 \%$ incidence of dural tear in patients who underwent surgery for degenerative disorders of the lumbar spine and found that patients age and level of surgeons training were factors contributing to the incidence of dural tears. ${ }^{10}$ In a retrospective study Wang et al. concluded 14\% incidence of ID in patients who had undergone lumbar surgery. ${ }^{2}$ In a long term review of 450 patients, who underwent lumbar spine surgery, Jones et al. reported a $4 \%$ rate of incidental durotomies recognized at surgery. ${ }^{11}$ In our study the incidence of ID was $6.5 \%$. Epstein et al. ${ }^{12}$ reported that patients without dural tear were younger than those with dural tear. Our study showed higher incidence of dural tears in patients in the third and the fourth decade, which can be explained by the fact that this age group contributed to the largest share of cases (107 cases) for lumbosacral prolapsed intervertebral discs, however increased incidence of dural tears in the elderly can be explained by reduced strength and elasticity of the dura in old age. Obesity is associated with an increased rate of ID in lumbar surgery. ${ }^{13}$ Our study showed high incidence of ID in obese patients. Many reports have described revision surgery as a significant risk factor for ID. ${ }^{10,13,14}$ The reported incidence varies from $15.9 \%$ in revision surgery to $3.5 \%$ in primary lumbar discectomy. ${ }^{10,14,15}$ We found that revision surgeries had an incidence of $12.9 \%$ as compared with first time surgery (5.53\%). Prior surgeries cause dural adhesions, absence of normal tissues and can lead to the loss of landmarks during surgery hence increased incidences. McMahon et al. reported that the most common instrument leading to ID is the Kerrison rongeur ${ }^{3}$ which was the same in our case as well.

Surgeon's fatigue appears to be a major determinant in our study since none of the inadvertent durotomy patients happened to be the first case of the day. This complication was more associated with Interlaminar discectomy (about $60 \%$ ). This could be explained by the fact that it was the most common surgery being performed at our institute. However technically it was found to be difficult to perform Interlaminar discectomy in patients with prolapsed intervertebral discs and Lumbar canal stenosis because of the smaller space and hence a smaller incision/access was included as an independent predictor for inadvertent durotomy.

Eismont et al. ${ }^{16}$ recommended the use of fascial graft in the treatment of large dural defects and suggested that small dural tears can be repaired with either running locked or simple sutures using a fat graft. Khan et al, ${ }^{17}$ found that subfascial drains were helpful in decompressing the subfascial space to prevent the build-up of CSF. Wang et al. ${ }^{2}$ used $4 / 0$ (or) 5/0 silk interlocking suture, gel foam, sub fascial drain and a layered closure. In our study, primary repair of all tears was done with $4 / 0$ prolene, with a fat and fascia graft and application of fibrin glue.

Based on our study the common factors leading to ID included presence of bony and ligamentous canal stenosis, instrument handling during flavectomy \& medial facetectomy, redo surgeries, smaller size of incisions, surgeon's fatigue, and age of the patient.

The most effective way to minimize the incidence of incidental durotomy is to make a conscious effort to prevent it by knowing the pre-op risk. Pre-operative planning and meticulous surgical technique are necessary to reduce the incidence of durotomies. A scale of predictors is proposed based on the factors on the patients who had this complication in our study, shown in Table 2. When we analysed our data, the factors which contributed most to ID in the study were tabulated and given a score of 1 , however since ID in revision surgeries were more than in the first surgeries, it was given a score of 3 so that its presence increases the risk factor to at least moderate. The number of cases with ID in our study group was too small to derive a statistical significance. Therefore, we propose application of this chart in clinical practice and its validation.

Limitations of our study were, there was lack of prospective and cohort-matched controlled studies, the numbers of ID were too low for a statistical analysis and this study did not account for several factors, such as experience level of the surgeon, spondylolisthesis, or synovial cysts, which are also risk factors for ID.

\section{Conclusions}

ID is an unwanted complication in spinal surgeries however it is avoidable. The predictors are bony and ligamentous canal stenosis, smaller surgical incisions, surgeon's fatigue, BMI of patient, age of the patient and revision surgery. By being aware of the risk status of a particular patient, surgeons can avoid inadvertent durotomy. A scale of predictors has been proposed. This may however need further validation.

Conflict of Interest: None

Source(s) of support: None 


\section{References}

1. Cammisa FP Jr, Girardi FP, Sangani PK, Parvataneni HK, Cadag S, Sandhu HS. Incidental durotomy in spine surgery. Spine (Phila Pa 1976). 2000;25(20):2663-7. https://doi.org/10.1097/00007632-200010150-00019

2. Wang JC, Bohlman HH, Riew KD. Dural tears secondary to operations on the lumbar spine. Management and results after a two-year-minimum follow-up of eighty-eight patients. J Bone Joint Surg Am. 1998;80(12):1728-32. https://doi. org/10.2106/00004623-199812000-00002

3. McMahon P, Dididze M, LeviAD. Incidental durotomy after spinal surgery: a prospective study in an academic institution. J Neurosurg Spine. 2012;17(1):30-6. https://doi.org/10.3171/2012.3.SPINE11939

4. Tafazal SI, Sell PJ. Incidental durotomy in lumbar spine surgery: incidence and management. European Spine Journal: Official Publication of the European Spine Society, the European Spinal Deformity Society, and the European Section of the Cervical Spine Research Society. 2005;14(3):287-90. https:// doi.org/10.1007/s00586-004-0821-2

5. Horwitz N H, Rizzoli H V; Herniated intervertebral discs and spinal stenosis.In. Post-operative complications of extracranial neurological surgery, Horwitz N Hand Rizzoli H V, (eds.). Williams and Wilkins, Baltimore, 1987:1-72.

6. Baker GA, Cizik AM, Bransford RJ, Bellabarba C, Konodi MA, Chapman JR, Lee MJ. Risk factors for unintended durotomy during spine surgery: a multivariate analysis. Spine J. 2012;12(2):121-6. https://doi.org/10.1016/j.spinee.2012.01.012

7. Burks CA, Werner BC, Yang S, Shimer AL. Obesity is associated with an increased rate of incidental durotomy in lumbar spine surgery. Spine (Phila $\mathrm{Pa}$ 1976). 2015;40(7):500-4. https://doi.org/10.1097/ BRS.0000000000000784

8. Wiese M, Kramer J, Bernsmann K, Ernst Willburger R. The related outcome and complication rate in primary lumbar microscopic disc surgery depending on the surgeon's experience: comparative studies. Spine J. 2004;4(5):550-6. https//doi. org/10.3171/2011.7.FOCUS11122
9. Blecher R, Anekstein Y, Mirovsky Y. Incidental dural tears during lumbar spine surgery: a retrospective case study of 84 degenerative lumbar spine patients. Asian Spine J. 2014;8(5):639-45. https://doi.org/10.4184/ asj.2014.8.5.639

10. SinAH, Caldito G, SmithD, Rashidi M, Willis B, Nanda A. Predictive factors for dural tear and cerebrospinal fluid leakage in patients undergoing lumbar surgery. J Neurosurg Spine. 2006 Sep;5(3):224-7. https:/doi. org/10.3171/spi.2006.5.3.224

11. Jones AA, Stambough JL, Balderston RA, Rothman $\mathrm{RH}$, Booth RE Jr. Long-term results of lumbar spine surgery complicated by unintended incidental durotomy. Spine (Phila Pa 1976). 1989;14(4):443-6. https://doi.org/10.1097/00007632-198904000-00021

12. Epstein NE. The frequency and etiology of intraoperative dural tears in 110 predominantly geriatric patients undergoing multilevel laminectomy with noninstrumented fusions. J Spinal Disord Tech. 2007;20(5):380-6. https://doi.org/10.1097/ BSD.0b013e31802dabd2

13. Smorgick Y, Baker KC, Herkowitz H, Montgomery D, Badve SA, Bachison C, et al. Predisposing factors for dural tear in patients undergoing lumbar spine surgery. J Neurosurg Spine. 2015; 22(5): 483-6, https//doi.org/10.3171/2015.1.SPINE13864

14. Yoshihara H, Yoneoka D. Incidental dural tear in spine surgery: analysis of a nationwide database. Eur Spine J. 2014;23(2):389-94. https://doi.org/10.1007/ s00586-013-3091-z.

15. Papadakis M, Aggeliki L, Papadopoulos EC, Girardi FP. Common surgical complications in degenerative spinal surgery. World J Orthop. 2013;4(2):62-6. https://doi.org/10.5312/wjo.v4.i2.62

16. Eismont FJ, Wiesel SW, Rothman RH. Treatment of dural tears associated with spinal surgery. J Bone Joint Surg Am. 1981;63(7):1132-6. PMID: 7024283.

17. Khan MH, Rihn J, Steele G, Davis R, Donaldson WF 3rd, Kang JD, Lee JY. Postoperative management protocol for incidental dural tears during degenerative lumbar spine surgery: a review of 3,183 consecutive degenerative lumbar cases. Spine (Phila Pa 1976). 2006;31(22):2609-13. https://doi.org/10.1097/01. brs.0000241066.55849.41 